\title{
INTUBATION STUDIES OF THE HUMAN SMALL INTESTINE. IV. CHEMICAL CHARACTERISTICS OF THE INTESTINAL CON- TENTS IN THE FASTING STATE AND AS INFLUENCED BY THE ADMINISTRATION OF ACIDS, OF ALKA- LIES AND OF WATER ${ }^{1}$
}

\author{
By W. G. KARR AND W. OSLER ABBOTT \\ WITH THE TECHNICAL ASSISTANCE OF \\ ALBERT B. SAMPLE \\ (From the Gastro-Intestinal Section of the Medical Clinic, Hospital of the University of \\ Pennsylvania, Philadelphia)
}

(Received for publication July 22, 1935)

The development of a practical technique by Miller and Abbott (1) for the prompt collection of jejunal and ileal contents from the normal human subject, using a double-lumened apparatus so arranged as to obstruct passage beyond the point of aspiration, has rendered possible for the first time a direct investigation of the chemical nature of these intestinal fluids comparable to the studies previously made on gastric and duodenal juices. The method permits, in addition, a more complete collection of duodenal contents than can be obtained with a single-lumened tube. Thus an opportunity is now available to make observations on material obtained in a satisfactory manner from any part of the small intestine of man.

In this presentation we report the results of chemical determinations made on contents from the duodenum, the jejunum and the ileum of individuals with apparently normal digestive tracts. They show the range in reaction, bicarbonate concentration and osmotic pressure, under fasting conditions and after the oral administration of hydrochloric acid, of sodium bicarbonate and of water. Some data on the chloride, calcium, phosphorous and total nitrogen concentrations are included. An attempt has been made to correlate the various observations. The results will be used as a basis of comparison for work now in progress in this Clinic on problems of intestinal secretion and absorption.

\section{METHODS}

1. Subjects. The observations are based on fifty-one intestinal intubations carried out on thirty individuals,

1 Aided by a donation from Mr. Samuel S. Fels and by grants from the Faculty Research Committee and from Smith, Kline and French Laboratories. some of whom were patients whose gastro-intestinal tracts were considered to be normal and some, paid healthy subjects. Each subject took the tube in the morning after a 14 to 16 hour fast. The specimens included samples obtained consecutively at one intubation as well as samples from repeated intubations of the same individual.

2. Intubation. The method $(1,2)$ involved the use of a double-lumened tube with a thin rubber balloon attached over the distal end of one lumen. This balloon, when distended in the duodenum by the injection of air, stimulates peristalsis sufficiently to sweep the apparatus rapidly along the intestine, and then, when in the desired position and somewhat less tense, serves as a dam to facilitate aspiration of the contents above it through fenestrations in the second lumen. The efficiency of the balloon in checking the flow of contents was clearly established by roentgen examination after the oral introduction of barium sulphate suspensions. The specimens were aspirated by a negative pressure of $70 \mathrm{~cm}$. of water, which is sufficient to conduct through a single lumen of a nine foot tube $150 \mathrm{cc}$. of intestinal juice per minute. As the end of the tube frequently reached the terminal ileum in the course of three hours after traversing the pylorus, the entire length of the small intestine was available for study.

Although both measurement of the length of the tube beyond the pylorus and fluoroscopy were employed, the exact point in the small intestine from which material was being aspirated was difficult to determine, except when near the cecum. Even when the tube was checked at the mouth and no more of it allowed to enter we observed that nevertheless more and more of the intestine tended slowly to assume a position above the balloon, thus causing the tube from time to time to reach an actually deeper level in the bowel. On one occasion, for instance, a balloon on a tube extending only four and a half feet beyond the pylorus lay in the upper ileum within three hours after it was swallowed, but after six hours, without any more tube being allowed to enter, it was found to be in the cecum. For this reason, and because we have found no abrupt change in the character of the contents or in the roentgen picture in different 
parts of the bowel, we have designated the regions studied as those reached by a tube extending $30,60,90,120$ and $150 \mathrm{~cm}$. below the pylorus. These distances, when reached in such a time interval as we are accustomed to allow, may, we believe be interpreted as indicating respectively upper jejunum, lower jejunum and upper, middle and lower ileum. Flouroscopic observation indicates that when with our technique the tube stands at $150 \mathrm{~cm}$. after three hours, the balloon is usually at a point just above the ileocecal valve.

3. Chemistry. The specimens were collected in all instances under oil. Chlorides were determined by a slight modification of the method of Wilson and Ball (3) using saturated $\mathrm{KMnO}_{4}$ as an aid in oxidation. The carbon dioxide content was determined by the method of Van Slyke and Stadie (4). The $\mathrm{pH}$ determinations were made immediately after collection by the balanced quinhydrone method of Meeker and Oser (5). For the determination of calcium the material was dried and ashed with a small amount of nitrate and sodium carbonate. The melt was taken up with a slight excess of acetic acid and after neutralizing to the proper $\mathrm{pH}$ the determination was continued by the micro method of Clark and Collip (6). The total phosphorus was determined on $2 \mathrm{cc}$. by wet ashing with concentrated sulphuric acid and 30 per cent hydrogen peroxide and completing the analysis by the method of Fiske and Subbarrow (7). Inorganic phosphorus was determined by the same method after precipitation with trichloracetic acid. This precipitation often does not give a clear filtrate, and only a few determinations were made. Total nitrogen was determined by the micro-Kjeldahl method on diluted specimens.

Our analyses indicate that the only significant, osmotically active solutes in the fasting intestinal contents are the chloride and bicarbonate salts. In Table I are presented data showing the close approximation between the sum of the chloride and bicarbonate anions and the total
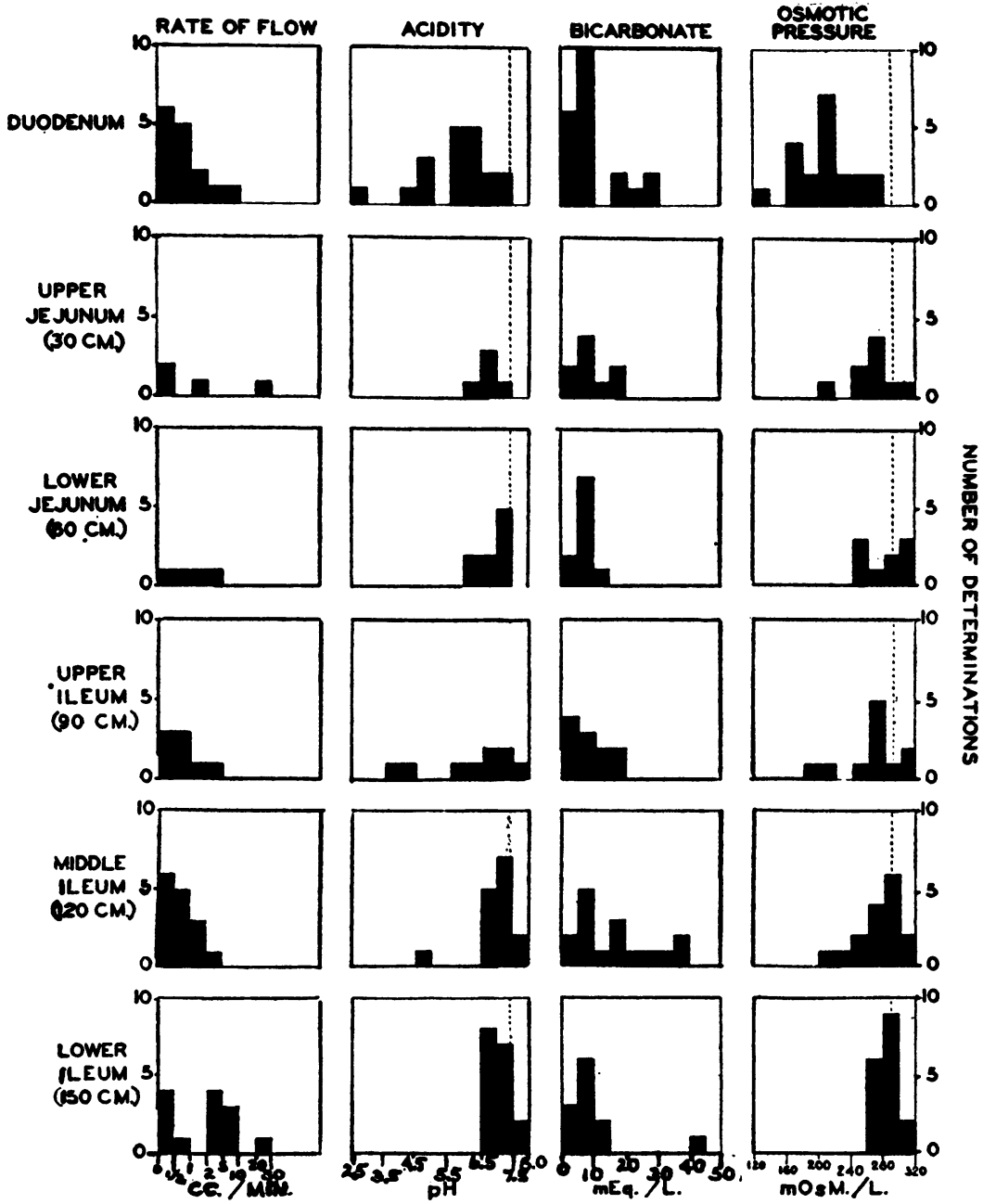

Fig. 1. Distribution of Results in the Total Group of Fasting Subjects Dotted lines indicate normal values for blood plasma. 
TABLE I

Comparison of the sum of the concentrations of the chloride and the bicarbonate anions with the total fixed base of intestinal contents

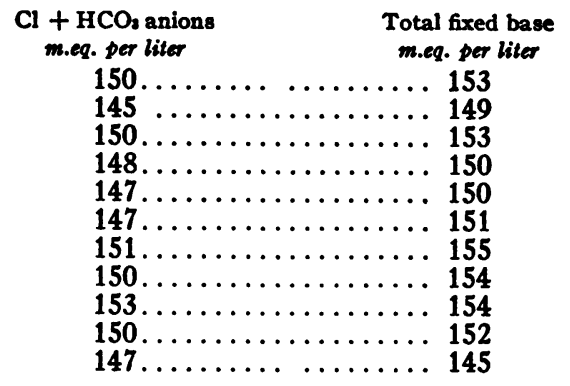

base. Gamble and McIver (8) showed a similar agreement in pure pancreatic juice. Gilman and Cowgill (9), in a study of relatively pure gastric juice, in which the chloride is the only anion, found that the osmotic pressure, as measured by Hill's (10) vapor pressure method and expressed as milliequivalents, was the same as the
300 we have assumed the fluid to be of approximately the same osmotic pressure as the blood serum.

\section{RESULTS}

\section{After fasting}

The data on rate of flow, reaction, bicarbonate concentration and osmotic pressure are represented in a distribution chart (Figure 1). Table II gives results from repeated intubations of a single individual.

(a) Rate of flow. As indicated in Figure 1 the rate of flow for 45 out of a total of 65 fasting specimens was $2 \mathrm{cc}$. or less per minute, and in half of these it was $0.5 \mathrm{cc}$. or less. It conformed to the description given by Miller and Abbott (2), being usually slow but extremely irregular. In the same individual on different occasions it was often more constant. Without exception it

TABLE II

Results from eleven intubations on the same subject (D. M.) in the fasting state

\begin{tabular}{|c|c|c|c|c|c|c|c|}
\hline Duodenum & $\begin{array}{l}\quad 1994 \\
\text { April } 23 \\
\text { April } 23 \\
\text { April } 23 \\
\text { May 3 } \\
\text { July } 18 \\
\text { September } 6 \\
\text { September } 13\end{array}$ & $\begin{array}{l}\text { number } \\
\text { III A } \\
\text { III B } \\
\text { III C } \\
\text { IV } \\
\text { VIII A } \\
\underset{\text { IX }}{\mathbf{X}}\end{array}$ & $\begin{array}{c}\text { cc. per minute } \\
2.5 \\
.88 \\
.76 \\
1.42 \\
.37 \\
.48\end{array}$ & $\begin{array}{l}5.74 \\
5.52 \\
5.93 \\
4.70 \\
6.50 \\
6.04\end{array}$ & $\begin{array}{c}\text { m.eq. per liter } \\
50.8 \\
75.4 \\
85.6 \\
93.4 \\
62.4 \\
132.6 \\
102.4\end{array}$ & $\begin{array}{r}\text { m.eq. per liter } \\
\\
5.8 \\
21.1 \\
4.3 \\
6.3 \\
5.1 \\
4.0\end{array}$ & $\begin{array}{c}\text { mOsM. per liter } \\
162 \\
214 \\
196 \\
138 \\
276 \\
213\end{array}$ \\
\hline Jejunum $(60 \mathrm{~cm})$. & June 1 & VI & 1.00 & 7.03 & 116.4 & 5.8 & 244 \\
\hline Upper ileum $(90 \mathrm{~cm})$. & March 19 & II A & & 6.10 & 128.6 & 2.3 & 262 \\
\hline Middle ileum (120 cm.) & $\begin{array}{l}\text { March } 19 \\
\text { March } 19 \\
\text { March } 13 \\
\text { May } 22 \\
\text { July } 9 \\
\text { July } 9 \\
\text { July } 18\end{array}$ & $\begin{array}{c}\text { II } \\
\text { II } \\
\text { I } \\
\text { VII } \\
\text { VII } \\
\text { VIII } \\
\mathbf{B} \\
\mathbf{B}\end{array}$ & $\begin{array}{r}.40 \\
1.05 \\
.58 \\
.72 \\
.68 \\
.18 \\
.28\end{array}$ & $\begin{array}{l}7.05 \\
7.21 \\
6.77 \\
7.15\end{array}$ & $\begin{array}{l}132.6 \\
126.0 \\
123.1 \\
101.0 \\
114.0 \\
104.6 \\
127.0\end{array}$ & $\begin{array}{r}6.5 \\
20.1 \\
15.0 \\
17.8 \\
35.6 \\
39.8 \\
3.9\end{array}$ & $\begin{array}{l}278 \\
292 \\
276 \\
238 \\
299 \\
289 \\
262\end{array}$ \\
\hline Lower ileum (160 cm.) & $\begin{array}{l}\text { September } 20 \\
\text { September } 20 \\
\text { September } 20\end{array}$ & $\begin{array}{l}\text { XI } \\
\text { XI } \\
\text { XI } \\
\mathbf{C}\end{array}$ & $\begin{array}{c}.28 \\
5.8 \\
.47\end{array}$ & $\begin{array}{l}7.16 \\
7.21 \\
7.31\end{array}$ & $\begin{array}{l}123.9 \\
128.2 \\
127.6\end{array}$ & $\begin{array}{l}10.4 \\
16.5 \\
17.0\end{array}$ & $\begin{array}{l}269 \\
289 \\
289\end{array}$ \\
\hline
\end{tabular}

chloride concentration found by analysis. Darrow and Hartmann (11) have determined that the calculated osmotic pressure of blood serum agrees very well with that determined by freezing point lowering, and that it approaches 300 milliosmoles per liter.

We have, therefore, as a sufficient approximation of the osmotic pressure of fasting intestinal contents, multiplied the sum of the chloride and bicarbonate anions, expressed as milliequivalents per liter, by two, and designated this figure as milliosmoles. When it approaches was intermittent, being sometimes rapid for a while then followed by complete cessation for an unpredictable interval. The few continuing high rates of flow, mostly from the ileum, since they were obtained on individuals who complained of mild abdominal distress, were due undoubtedly to an increased gastro-intestinal motility. Irrespective of the location from which aspiration was 
taking place, collections of gas appeared interspersed between columns of fluid. The material in its gross appearance conformed, with slight variation, to the description of Miller and Abbott (2), being a somewhat viscid fluid, of amber to greenish color, and it usually contained fine flecks of mucus and other debris which settled on standing.

(b) Reaction. The $\mathrm{pH}$ was very variable, ranging from 2.64 to 7.80 . There was a tendency for the contents to become more alkaline lower in the intestine, though distinctly acid specimens ( $\mathrm{pH} 4.8$ ) were occasionally recovered even from the ileum.

(c) As would be anticipated from the wide range of $\mathrm{pH}$, the bicarbonate concentration was variable, our extremes being 1.3 and 45.5 m.eq. per liter.

(d) Osmotic pressure. The contents, especially from the upper intestinal tract, were often

TABLE III

Concentrations of calcium, nitrogen and phosphorus in the intestinal contents of fasting subjects at various levels

\begin{tabular}{|c|c|c|c|}
\hline $\begin{array}{l}\text { Distance beyond } \\
\text { the pylorus }\end{array}$ & Calcium & $\begin{array}{c}\begin{array}{c}\text { Total } \\
\text { phosphorus }\end{array}\end{array}$ & $\begin{array}{c}\text { Total } \\
\text { nitrogen }\end{array}$ \\
\hline 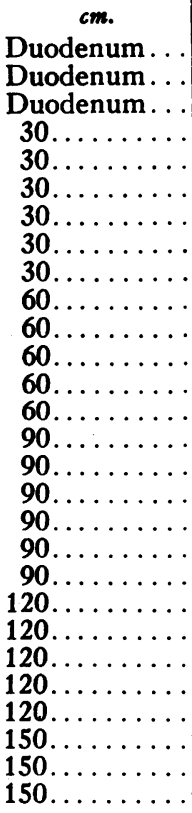 & $\begin{array}{r}8.0 \\
5.2 \\
5.6 \\
11.6 \\
12.8 \\
5.4 \\
8.0 \\
5.8 \\
5.4 \\
5.2\end{array}$ & \begin{tabular}{|c|} 
mgm. per $100 c c$. \\
\\
5.5 \\
4.7 \\
\\
10.0 \\
13.2 \\
7.1 \\
7.2 \\
7.3 \\
\\
7.1
\end{tabular} & $\begin{array}{c}\text { mgm. per } 100 c c . \\
61 \\
33 \\
63 \\
56 \\
\\
45 \\
45 \\
73 \\
55 \\
50 \\
109 * \\
54 \\
40\end{array}$ \\
\hline Average.. & 7.7 & 6.8 & 53 \\
\hline
\end{tabular}

* Not averaged. hypotonic as compared with blood plasma. In their passage down the tract, however, isotonicity was usually attained, but never exceeded. The chloride concentration was in reciprocal relationship with the bicarbonate content, thus maintaining the osmotic pressure. The chloride ranged from 50.6 to 150.6 m.eq. per liter (296 to 880 mgm. $\mathrm{NaCl}$ per $100 \mathrm{cc}$.).

(e) Calcium, phosphorus and nitrogen. The calcium concentration was usually below the normal blood level. A few analyses indicated that practically all of the phosphorus was in the inorganic form, its concentration was usually above that of blood plasma. Both calcium and phosphorus tended to be more concentrated in the upper. intestine. As the few analyses indicated that about one-half of the total nitrogen was precipitable by zinc hydroxide, the fasting protein content was very low.

\section{After hydrochloric acid and sodium bicar- bonate administration}

When hydrochloric acid solution $(0.16 \mathrm{~N})$, isotonic with blood plasma, was introduced into the stomach by tube in $50 \mathrm{cc}$. quantities the resultant influence on the chemistry of the intestinal contents at various levels is shown in Figure 2. Hydrochloric acid of this concentration is apparently held in the stomach, and released into the intestine in small quantities so that neutralization is rapidly attained. No immediate increase in rate of flow was observed, but in two cases an increase occurred about one hour after giving the acid. No decrease in the $\mathrm{pH}$ but rather a tendency to an increase was noted, showing that the alkaline intestinal fluids are present in excess. Isotonicity with the blood plasma was maintained.

The response to isotonic sodium bicarbonate solution was in marked contrast to that which followed the administration of isotonic hydrochloric acid (Figure 3). The bicarbonate left the stomach very rapidly as is shown by the immediate increase in the rate of flow, in the bicarbonate content and in the alkalinity of the intestinal contents. Sodium bicarbonate in 5 per cent solution also left the stomach relatively rapidly. That it was not held until isotonicity was established is indicated by the osmolar concentration of the intestinal fluid rising appreciably above 300 milliosmoles. When 


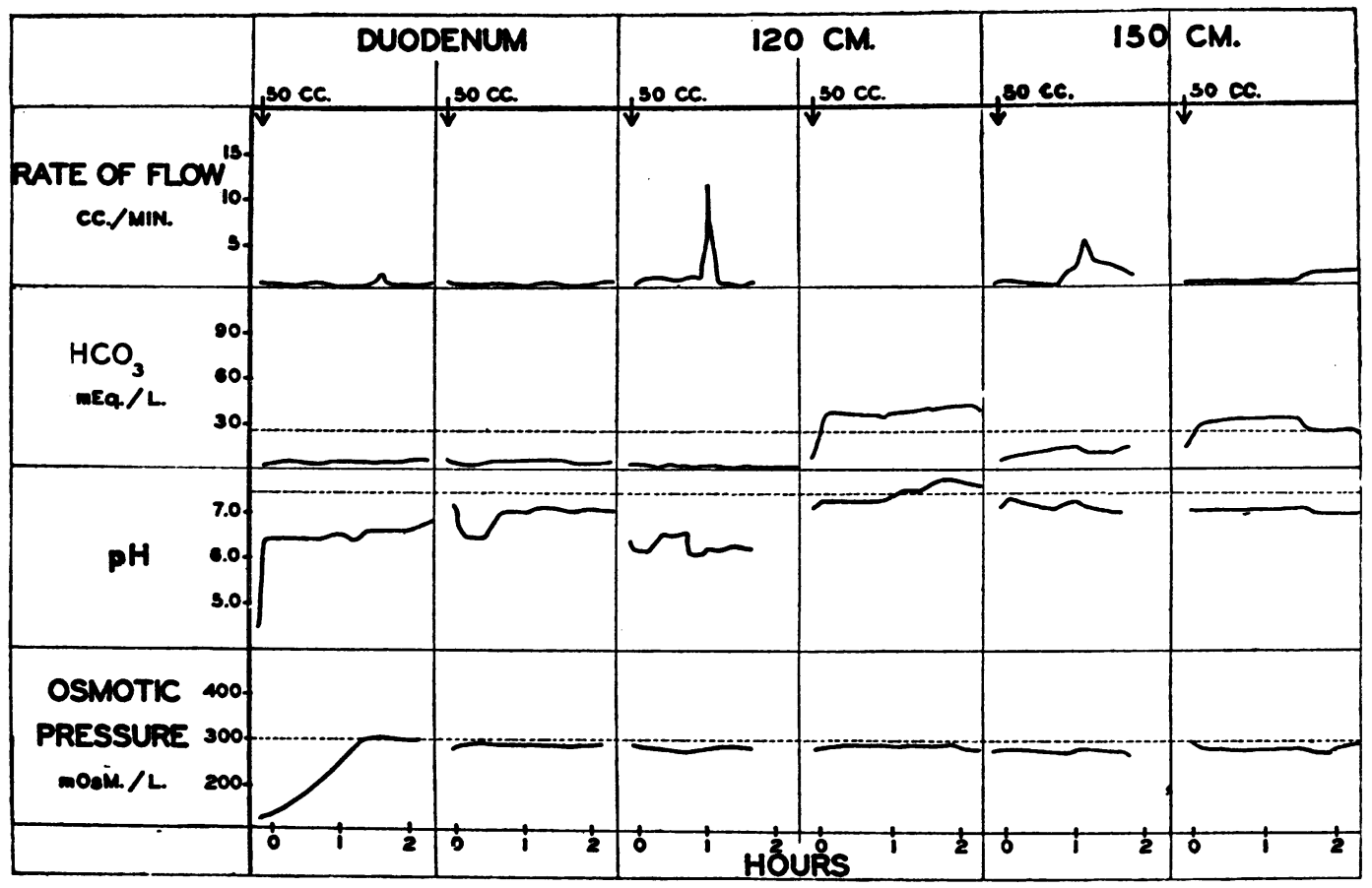

Fig. 2. Curves to Show the Effects of the Oral Administration of Isotonic Hydrochloric Acid Solution $(0.16 \mathrm{~N}$ ) on the Contents of the Duodenum and of the Ileum (120 and $150 \mathrm{~cm}$. Below the Pylorus).

Dotted lines indicate normal values for blood plasma. Arrows indicate time of administration.

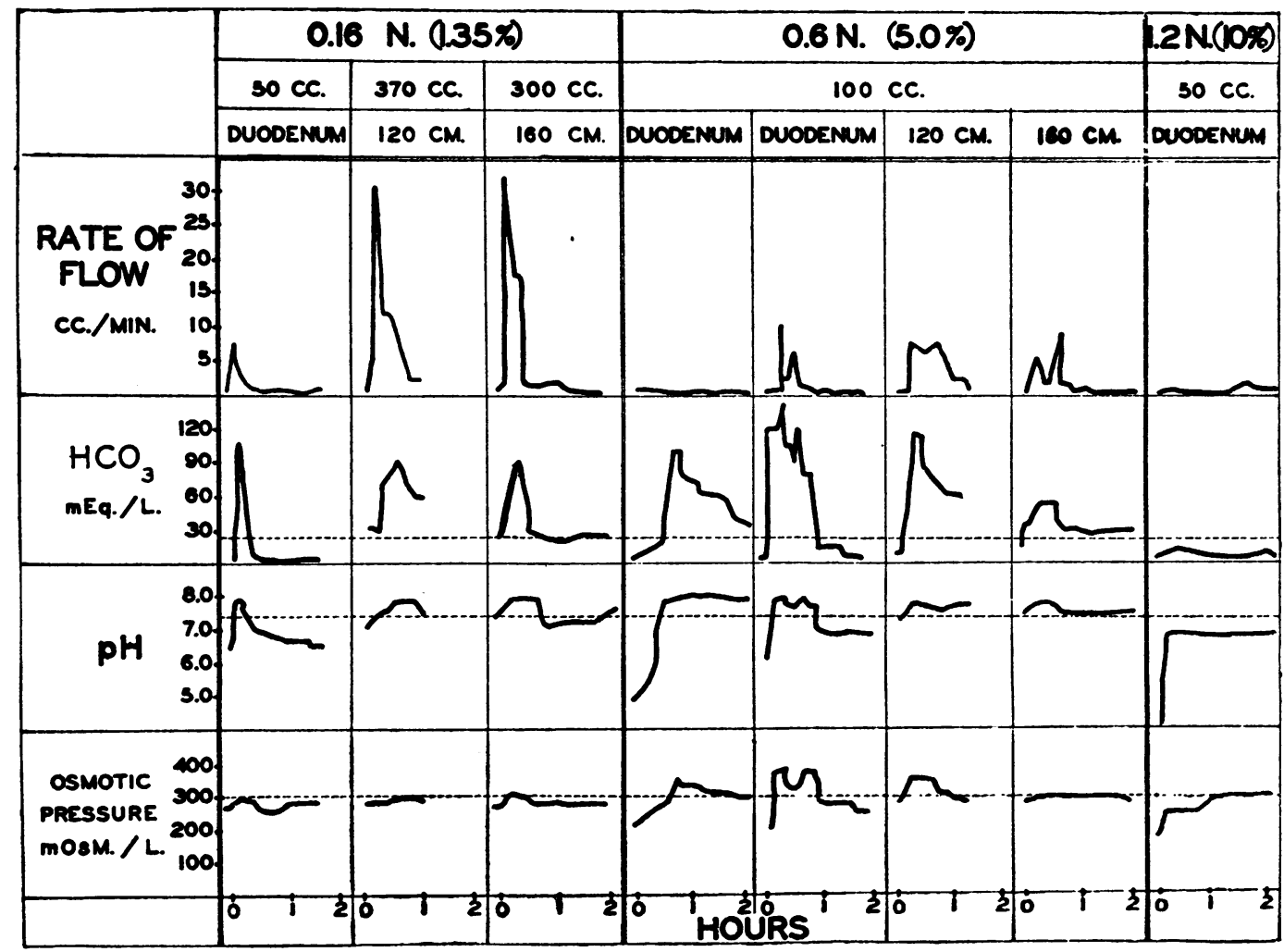

Fig. 3. Curves to Show the Effects of the Oral Administration of Isotonic and Hypertonic Solutions of Sodium Bicarbonate on the Contents of the Intestinal Tract

Dotted lines indicate normal values for blood plasma. Solutions were administered at zero time. 
in a single experiment a stronger solution of sodium bicarbonate (10 per cent) was given it was retained by the stomach until diluted. This is definitely indicated by the absence of an appreciable increase in the bicarbonate ion of the duodenal fluid. In the latter instance, furthermore, bicarbonate was present in the stomach three and onehalf hours after its administration, in contrast to some experiments with isotonic bicarbonate solution in which the gastric juice again became acid within thirty minutes.

\section{After water}

The data obtained on specimens from three different levels in the intestine after the subject had drunk $400 \mathrm{cc}$. of water are plotted in Figure 4.

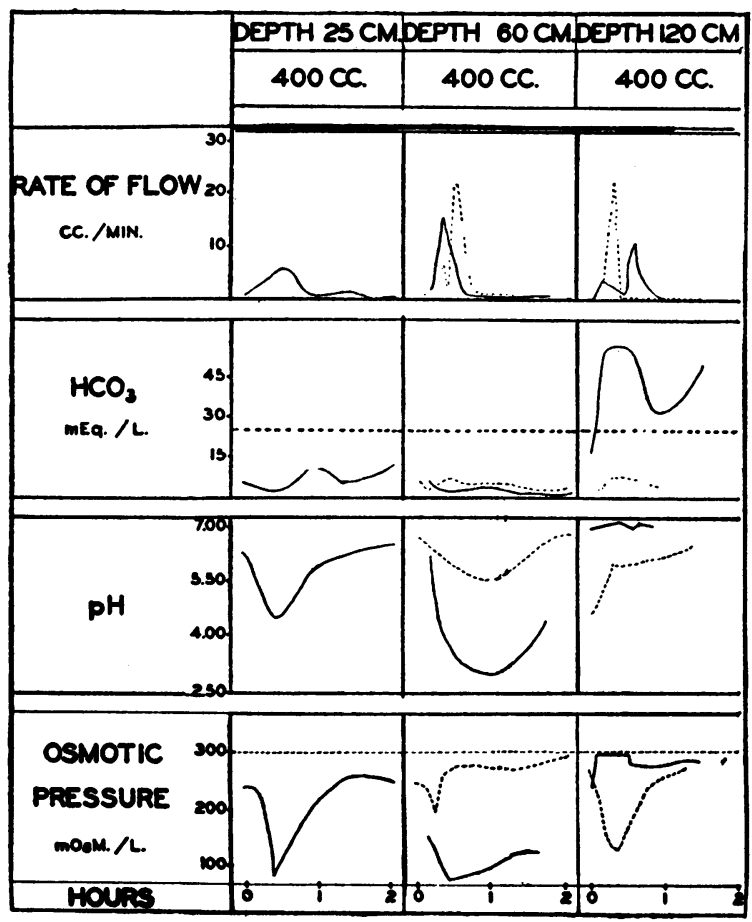

Fig. 4. Curves to Show the Effects of the Oral Administration of Water on the Contents from Five Fasting Subjects.

Each subject is represented by a different type of line. The water was administered at zero time.

In four out of five cases, as shown by the prompt increase in the rate of flow, the water left the stomach rapidly. With this sweeping out of the basal acid secretions of the stomach the $\mathrm{pH}$ of the intestinal fluid decreased. The osmotic pressure of the fluid also was lowered until approximate equilibrium was established after a variable interval. In one case in which only a slightly increased rate of flow occurred within the first half hour, the influence of the alkaline intestinal fluid predominated as indicated by the increase in bicarbonate, the higher $\mathrm{pH}$ and the maintenance of isotonicity.

\section{DISCUSSION}

The data covered in this report are based entirely on a chemical study of intestinal contents as they normally occur and not of pure intestinal secretion. Chemical analyses of intestinal juices per se, without an admixture of substances from above, secured by the use of a three-lumened double-ballooned apparatus (12) that allows the fluid to be collected from an isolated segment of bowel, will be reported separately by Abbott and Karr (13).

Since the contents at any one point are a mixture of saliva, gastric juice, bile, pancreatic secretion and succus entericus originating above the point of collection, the composition depends primarily upon the ingredients of these separate secretions and secondarily upon the chemical reactions that occur among them. Gastric juice is hypotonic with respect to blood plasma. The acid gastric juice enters the duodenum and there comes in contact with secretions of alkaline reaction and of isotonic composition (8). The fasting contents of the small intestine beyond the duodenum are essentially a mixture of two fluids, gastric and duodenal, and they have a tendency to assume the characteristics of whichever may predominate at the time.

The great variation in the $\mathrm{pH}$ of the fasting intestinal contents is associated with a marked variation in the motility of the stomach and the intestine and, to a less extent, with a variation in the acidity of the fasting stomach contents and in the amount of pancreatic secretion. If the acid gastric juice while fasting leaves the stomach rapidly and is carried down the intestine by active peristalsis, the $\mathrm{pH}$ at any level tends to be low. If the progress of the contents is slower, complete neutralization occurs and sometimes, when intestinal secretions are in excess, an alkaline reaction results. Roentgenological examination supports 
this relationship to motility. Such observations as apply to the duodenum are in keeping with the results of many similar studies previously made on man. With regard to the jejunum and ileum, only $\mathrm{McClendon}$ and his associates (14) have recorded the reaction in intact subjects, none of whom was in the fasting state. The most nearly comparable studies on animals are those of Mann and Bollman (15), who have showed in fistula dogs that the reaction of the intestinal content varies approximately in the same manner as that reported in this paper.

The studies of osmotic pressure of the intestinal contents show a wide variation from hypotonicity to practical isotonicity with the blood plasma. Two factors tend to produce a low osmotic pressure in the duodenum: the presence of hypotonic solutions from the stomach and neutralization. The following equation shows the neutralization of isotonic hydrochloric acid by isotonic sodium bicarbonate:

$\underset{\substack{\mathrm{HCl} \\ 160 \text { m.eq. } \\ \text { per liter }}}{\mathrm{H}}+\underset{\substack{160 \mathrm{~m} . e q . \\ \text { per liter }}}{\mathrm{NaHCO}_{3}}=\underset{\substack{80 \text { m.eq. } \\ \text { per liter }}}{\mathrm{NaCl}}+\underset{\text { (absorbed) }}{\mathrm{CO}_{2}}$

The carbon dioxide is very readily absorbed (16) and the resultant state of hypotonicity persists until equilibrium is established by the absorption of water or the diffusion of salt into the fluid. In any event osmotic equilibrium is usually attained, although if motility is very rapid, fluids with an acid $\mathrm{pH}$ and a low osmotic pressure may be found in the lower small intestine. When the motility is slow the fluids are neutral or alkaline and isotonic with blood plasma.

The bicarbonate content obviously varies with the hydrogen ion concentration. When the intestinal $\mathrm{pH}$ is in the neighborhood of 7.4 the bicarbonate content often approximates that of blood plasma. Variations are probably due to greater variations in the carbon dioxide tension. How much of the bicarbonate for neutralization comes from the pancreatic juice and how much through the intestinal wall is unknown. In the duodenum the pancreatic bicarbonate is probably the more important factor. In intestinal segments which have been blocked off, however, as will be shown in a subsequent presentation (13), certain stimuli may provoke a secretion of bi- carbonate greatly in excess of its concentration in the blood plasma.

The chief function of the chloride ion in its reciprocal relationship to the bicarbonate ion would seem to be that of maintaining osmotic pressure. That it is present in the intestinal fluid in greater concentration than in blood plasma may not indicate a specific secretory action of the intestinal wall but rather an equilibrium of the only anion available to maintain osmotic pressure.

It is fully realized that the presence in the intestinal tract of the tube and the inflated balloon may disturb to some extent its normal chemical physiology. The variations in the chemical data on an individual intubated on different occasions, however, would seem to be due to functional variations beyond control and occurring in spite of the fact that the apparatus always, in our work, has been introduced and maintained under constant conditions.

\section{SUM MARY}

(1) A technique of intubation which makes practical the recovery of contents from approximately any desired portion of the intact human small intestine has been employed in a study of the chemical characteristics of the normal bowel under varying conditions.

(2) Under fasting conditions it has been demonstrated (a) that the flow of contents into any part of the small intestine is usually less than 1 cc. per minute; $(b)$ that the acidity of the contents is greatest in the duodenum, diminishing gradually toward a neutral or even a slightly alkaline reaction in the lower ileum; $(c)$ that the bicarbonate concentration is related to the reaction of the contents, and $(d)$ that the duodenal contents if acid and in the process of neutralization are uniformly hypotonic, but that if neutral or alkaline they approach closely the osmotic state of the ileal contents which are essentially in equilibrium with the blood plasma.

(3) After the oral administration of a solution of hydrochloric acid isotonic with the body fluids, the contents of the stomach usually pass slowly into the duodenum, where they are completely neutralized by the bicarbonate content of the latter and attain osmotic equilibrium with the body.

(4) After the administration of an isotonic solution of sodium bicarbonate, a very rapid evac- 
uation of the stomach occurs; but after a 5 per cent solution, the discharge is less rapid though still sufficient to produce distinctly alkaline and hypertonic duodenal and intestinal contents. After a 10 per cent solution, however, gastric retention occurs to such an extent that within two hours no increase in the bicarbonate content or alkalinity of the duodenal contents can be demonstrated.

(5) After the administration of $400 \mathrm{cc}$. of water, the gastric contents pass into the duodenum with sufficient rapidity to render the intestinal fluids acid, and to lower their osmotic pressure.

\section{BIBLIOGRAPHY}

1. Miller, T. G., and Abbott, W. O., Intestinal intubation: A practical technique. Am. J. M. Sc., 1934, 187, 595.

2. Miller, T. G., and Abbott, W. O., Small intestinal intubation: Experiences with a double lumened tube. Ann. Int. Med., 1934, 8, 85.

3. Wilson, D. W., and Ball, E. G., A study of the estimation of chloride in blood and serum. J. Biol. Chem., 1928, 79, 221.

4. Van Slyke, D. D., and Stadie, W. C., The determination of the gases of the blood. J. Biol. Chem., 1921, 49, 1.

5. Meeker, G. H., and Oser, B. L., Titrametric double hydrogen or quinhydrone electrode systems for hydrion determination; applications to urine and blood. J. Biol. Chem., 1926, 67, 307.

6. Clark, E. P., and Collip, J. B., A study of the Tisdall method for the determination of blood serum cal- cium with a suggested modification. J. Biol. Chem., 1925, 63, 461.

7. Fiske, C. H., and Subbarrow, Y., The colorimetric determination of phosphorus. J. Biol. Chem., 1925, 66, 375.

8. Gamble, J. L., and McIver, M. A., Acid-base composition of pancreatic juice and bile. J. Exper. Med., 1928, 48, 849.

9. Gilman, A., and Cowgill, G. R., Osmotic relations between blood and body fluids. II. The osmotic relation of blood and gastric juice. Am. J. Physiol., 1933, 103, 143.

10. Hill, A. V., A thermal method of measuring the vapour pressure of an aqueous solution. Proc. Roy. Soc. London, 1930, A127, 9.

11. Darrow, D. C., and Hartmann, A. F., A comparison of the calculated and determined osmolar concentration of normal serum. Am. J. Dis. Child., 1929, 37, 51.

12. Abbott, W. O., and Miller, T. G., Intubation studies of the human small intestine. III. A technique for the collection of pure intestinal secretion and for the study of intestinal absorption. J. A. M. A. (In press.)

13. Abbott, W. O., and Karr, W. G., Unpublished results.

14. McClendon, J. F., Bissel, F. S., Lowe, E. R., and Meyer, P. F., Hydrogen ion concentration of the contents of the small bowel. J. A. M. A., 1920, 75, 1638.

15. Mann, F. C., and Bollman, J. L., The reaction of the content of the gastro-intestinal tract. J. A. M. A., 1930, 95, 1722.

16. McIver, M. A., Redfield, A. C., and Benedict, E. B., Gaseous exchange between the blood and the lumen of the stomach and intestines. Am. J. Physiol., 1926, 76, 92. 